\title{
Analysis of Hydraulic Properties of Indian Forest Soil
}

\author{
Shwetha Prasanna \\ Department of Civil Engineering, Don Bosco College of Engineering, Fatorda, Goa, India \\ Email:shwethaprasanna@gmail.com
}

\begin{abstract}
Soils are a product of the factors of formation and continuously change over the earth's surface. The analysis of the spatial variability of soil properties is important for land management and construction of an ecological environment. Soils are characterized by high degree of spatial variability due to the combined effect of physical, chemical or biological processes that operate with different intensities and at different scales. The spatial variability of soil hydraulic properties helps us to find the subsurface flux of water. The most frequently used hydraulic properties are soil water retention curve and saturated hydraulic conductivity. Both these hydraulic properties exhibit a high degree of spatial and temporal variability. The primary objective of this study was to analyze the spatial variability of hydraulic properties of forest soils of Pavanje river basin. Correlation analysis technique has been used to analyze various soil properties. Spatial variability of the forested hillslope soils at different depths varied considerably among the soil hydraulic properties. The spatial variability of water retention at all the different pressure head is low at the top layers, and increases towards the bottom layers. The saturated hydraulic conductivity is almost same in the top layers, but more in the bottom layers of forest soil.
\end{abstract}

Keywords: water retention, saturated hydraulic conductivity, spatial variability, hydraulic property, forest soil

\section{Introduction}

The spatial variability of soil hydraulic properties helps us to find the subsurface flux of water. In order to simulate water flow and solute transport process under field scale or to assess the hydrological response using models, not only determination of soil hydraulic properties in a large number of points but detailed features of spatial variability exhibited from these properties are also required [1]. The most frequently used hydraulic properties are soil water retention curve and saturated hydraulic conductivity. Both these hydraulic properties exhibit a high degree of spatial and temporal variability [2]. Soil moisture retention curve is important for understanding and predicting a range of hydrological processes including flooding, erosion and solute transport, and land atmosphere interactions. Water retention characteristics exhibit heterogeneous distribution in both horizontal and vertical space. Spatial distribution of water content at field capacity and permanent wilting point at different zones of a farm governs the available water for plant growth. The field capacity and permanent wilting point play key roles in crop selection for different blocks of a farm, and in scheduling irrigation of crops in a field. Saturated hydraulic conductivity $\left(\mathrm{k}_{\mathrm{s}}\right)$ is the other important soil hydraulic property having the highest statistical spatial variability [3]. It is difficult to characterize because of its high variability even over short distances, and measurement methods typically require considerable time and resources. The results indicate that soil water dynamics is strongly affected by the variability of saturated soil hydraulic conductivity, even in homogenous anthropogenic soils. This information may have a strong impact in irrigation management and subsurface drainage efficiency as well as other water conservation issues.

While, many researchers have studied the horizontal variation and temporal changes of soil moisture [4] little attention has been paid to the profile features of soil moisture retention and saturated hydraulic conductivity [5]. The primary motivation for conducting this study was the lack of spatial study on soil physical and hydraulic properties of Pavanje river basin soils. Correlation analysis technique has been used to analyze various soil properties. This study characterized the profile types as well as additional profile features of various soil properties (particle size distribution, bulk density, organic matter content, soil water retention data and saturated hydraulic conductivity), and also quantified the spatial variation of soil properties at layers under the study area.

\section{Materials and methodology}

In the present study, the Pavanje river basin in Dakshina Kannada district of coastal Karnataka is considered. The Pavanje river originates in the foothills of Western Ghats and flows towards west to join the Arabian Sea and lies between North latitudes $12^{\circ} 57^{\prime} 30^{\prime \prime}$ to $13^{\circ} 07^{\prime} 30^{\prime \prime}$ and East longitudes $74^{\circ} 45^{\prime} 00^{\prime \prime}$ to $75^{\circ} 02^{\prime} 30^{\prime \prime}$. The basin lies within the Dakshina Kannada district of Karnataka State, India. Soil sampling was carried out on a forested 
hillslopes of the Pavanje river basin. A total of fifty six soil samples were collected from eight different elevations distributed from the crest to the footslope. For the each elevation, physical properties and soil water retention data of seven soil layers with the thickness of 10, 20, 30, 40, 50, 60 and $75 \mathrm{~cm}$ were determined.

All the undisturbed and disturbed soil samples collected were subjected to laboratory measurements to determine bulk density, particle-size distribution, specific gravity, porosity, organic carbon content and soil water retention characteristics. Undisturbed soil samples were oven dried at $105^{\circ} \mathrm{C}$ to determine dry bulk density. Total porosity was calculated from the measured oven-dry bulk density and a soil particle density by using the relationship of (1-bulk density/particle density). Organic carbon content was determined with the Walkley and Black method. Organic matter was then calculated by a factor of 1.724 (Van Bemmelen's Correction Factor). Particle-size distribution was determined using sieve analysis and hydrometer. Sand, silt and clay contents are expressed as a percentage by mass of the fine earth fraction and soil texture is identified according to the United States Department of Agriculture (USDA) system of particle-size classification. Soil water retention data at 33,100,300,500, 1000 and1500 kPa matric potentials were measured using pressure plate apparatus. Soil samples were pressurized adequately and weighed at every potential.

The overall methodology adopted in this study focused on analyzing spatial characteristics of measured soil physical and hydraulic properties. Qiu et al. [6] proposed computation of several variables to characterize temporal and spatial variability in a quantitative manner. Calculations of several variables used in this study are demonstrated as follows: Let the soil properties of site $I$ and the layer $j$ be expressed as $M_{i, j}, N_{p}$ is the number of sites and $N_{l}$ is number of sampling layers or depths. The following variables may be defined as:

1) Mean of soil variable of site $i,\left(M_{i}\right)$

$$
M_{i}=\frac{1}{N_{l}} \sum_{j=1}^{N_{l}} M_{i, j}
$$

2) Mean of soil variable at soil layer $j,\left(M_{j}\right)$

$$
M_{j}=\frac{1}{N_{p}} \sum_{i=1}^{N_{p}} M_{i, j}
$$

3) Profile variability of soil variable on plot, $i,\left(V P_{i}\right)$

$$
V P_{i}=\sqrt{\frac{N_{l} \sum_{j=1}^{N_{l}}\left(M_{i . j}\right)^{2}-\left(\sum_{j=1}^{N_{l}} M_{i, j}\right)^{2}}{N_{l}\left(N_{l}-1\right)}}
$$

4) Spatial variability of layered averaged soil variable at soil layer $j$, $\left(V S_{j}\right)$

$$
V S_{j}=\sqrt{\frac{N_{p} \sum_{i=1}^{N_{p}}\left(M_{i . j}\right)^{2}-\left(\sum_{i=1}^{N_{p}} M_{i, j}\right)^{2}}{N_{p}\left(N_{p}-1\right)}}
$$

The four variables defined by Eqs. (1) to (4) were computed for five sites $\left(N_{p}\right)$ in agricultural land and eight elevations in forested hillslopes of the Pavanje river basin at different depths $\left(N_{l}\right)$ for both physical and hydraulic properties.

\section{Results and discussion}

An analysis was carried out to understand how soil moisture retention data and saturated hydraulic conductivity vary across the different elevations within the forested hillslope area. In order to collect the more information on hydraulic properties of the forested hillslopes, this study investigated the different variables of the soil water retention curve and the saturated hydraulic conductivity properties of forest soils of the Pavanje river basin. The present study computed four different variables i.e., mean of the elevations, mean at soil layers, profile variability of the elevations and spatial variability at layers for soil water retention curve and saturated hydraulic conductivity using the Eqs. (1) to (4). The bar charts are drawn for all these variables of the soil water retention curve and saturated hydraulic conductivity. In bar charts, number of elevations 1 to 8 represents $30 \mathrm{~m}$ to $120 \mathrm{~m}$ elevations and layers $1,2,3,4,5,6$ and 7 represent 10,20,30, 40, 50, 60 and $75 \mathrm{~cm}$ respectively.

At first, the present study considered the water retention at $-33 \mathrm{kPa}$ pressure head, $\left(\theta_{33}\right)$. Mean of the different elevations was found out using the Eq. (1). To find the mean $\left(\theta_{33}\right)$ of the elevation, the percentage of $\left(\theta_{33}\right)$ from all the depths (layers) from 10 to $75 \mathrm{~cm}$ at one elevation was considered and computed the mean sand of that elevation using the Eq. (1). The same procedure was repeated for the other remaining elevations also. Only at the top two elevations, mean water retention was relatively high when compared to other elevations i.e. at $105 \mathrm{~m}$ elevation $(26 \%)$ and $120 \mathrm{~m}$ elevation $(23.57 \%)$. Some variations were observed in the other elevations ranging from $18.71 \%$ to $22.29 \%$. Then mean water retention at $-33 \mathrm{kPa}$ at each soil layers (depths) from 10 to $75 \mathrm{~cm}$ was 
computed using the Eq. (2). Here the percentage of water retention at $-33 \mathrm{kPa}$ was taken from one particular depth (layer) of each elevation and mean water retention at $-33 \mathrm{kPa}$ at that depth (layer) was determined. It could be noticed that, from first layer to third layer, mean $\theta_{33}$ increased in the range of $21.5 \%$ to $22.38 \%$ and then it was almost same in other bottom layers, but in seventh layer i.e. at $75 \mathrm{~cm}$ depth, it was quite low about $20.13 \%$. The profile variability of water retention at $-33 \mathrm{kPa}$ was computed using the Eq. (3). At one elevation, by considering percentage of water retention at $-33 \mathrm{kPa}$ from all depths, the profile variability was determined. The same procedure was followed for other elevations also. Higher profile variability was observed at the top, middle and bottom most elevations $(30 \mathrm{~m}, 75 \mathrm{~m}$ and $120 \mathrm{~m})$ in range of $1.9 \%$ to $2.5 \%$ and lowest in third elevation $(0.49 \%)$. In the remaining elevations, minor differences were found. Spatial variability was less in sixth layer $(1.91 \%)$ and increased in third elevation (3.34\%). In other elevations, variations were found ranging from $2.74 \%$ to $3.07 \%$. Figure 1 , shows the different variables of water retention at $-33 \mathrm{kPa}$.

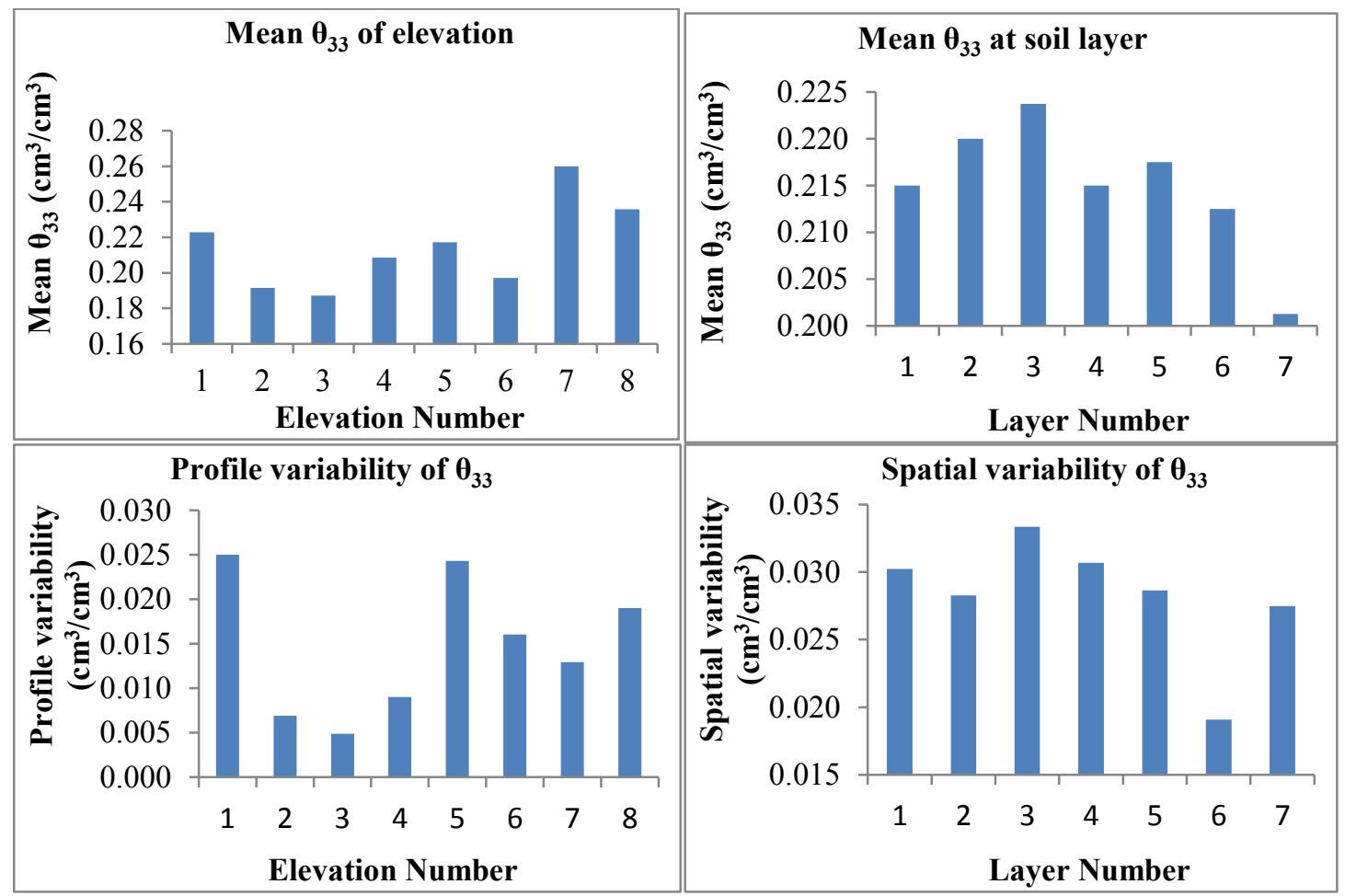

Figure 1: Different variables of $\theta_{33}$

This study was then taken up to determine the different variables of water retention at $-100 \mathrm{kPa}$ pressure head, $\left(\theta_{100}\right)$. Mean water retention at $-100 \mathrm{kPa}$ was computed for different elevations. It was more at the top two elevations i.e. at $105 \mathrm{~m}$ and $120 \mathrm{~m}$ about $20.43 \%$ and $19.86 \%$ respectively, minimum in the third elevation $(13.14 \%)$ and some differences were found in other elevations ranging from $14.86 \%$ to $18.14 \%$. Mean $\theta_{100}$ at layers was then computed; it increased from first layer to third layer (17\% to $18 \%)$ and then it decreased from $18 \%$ to $16 \%$ in the bottom layers. Profile variability of $2.88 \%$ was observed in first elevation (at $30 \mathrm{~m}$ ) and attained minimum $(0.69 \%)$ in the third elevation. In other elevations, small differences were found ranging from $1.21 \%$ to $1.81 \%$. Spatial variation was almost same in all the layers $(3 \%)$, quite low in the sixth layer $(2.43 \%)$ and more in the third layer $(3.06 \%)$.

Water retention at $-300 \mathrm{kPa}$ pressure head, $\left(\theta_{300}\right)$ was then taken into consideration and calculated the different variables. Mean water retention was higher at the top two elevations i.e., at seventh and eighth elevations (16.71 and $16.57 \%$ ) respectively. Even in the first elevation i.e. at bottom most elevation, mean water retention was quite more $(16.43 \%)$. In second and third elevations, it decreased and again increased in other elevations $(15.71 \%$ to $16.71 \%)$ except in sixth elevation, where it decreased to $14 \%$. Mean $\theta_{300}$ at layers were found; it increased in the top layers i.e. from first layer to third layer in the range of $15.13 \%$ to $16 \%$ and then decreased from fourth layer to seventh layer in the range of $15.5 \%$ to $14 \%$. High profile variation was observed in the first elevation $(2.7 \%)$, and then it decreased in the other three elevations to $0.76 \%$. Again in fifth elevation, it increased to $2 \%$ and then suddenly decreased to $0.82 \%$ in sixth elevation. From sixth elevation, mean water retention was once again increased from $0.82 \%$ to $1.51 \%$. Some spatial variations were observed across the layers. It was about $2.23 \%$ to $2.93 \%$ in the top layers and in the bottom layers, $1.69 \%$ to $2.25 \%$. 
The analysis was then carried out for the different variables of water retention at $-500 \mathrm{kPa}$ pressure head, $\left(\theta_{500}\right)$. Mean water retention at $-500 \mathrm{kPa}$ was comparatively less in the bottom elevations about $11 \%$ to $11.86 \%$ and increased in the top elevations (12.29\% to $14.43 \%)$. Mean $\theta_{500}$ at different layers was then calculated; it was almost same in the top layers i.e., up to fourth layer (13\%) and then decreased to $12 \%$ in the bottom layers. Profile variability was more in fifth elevation about $2.31 \%$, in other elevations it was ranging from $0.58 \%$ to $1.38 \%$. More spatial variability was observed in second layer, about $2.05 \%$ and then it decreased to $1.19 \%$ in the sixth layer. In first and last layers, spatial variability was almost same (1.6\%). The results are shown in Figure 2.

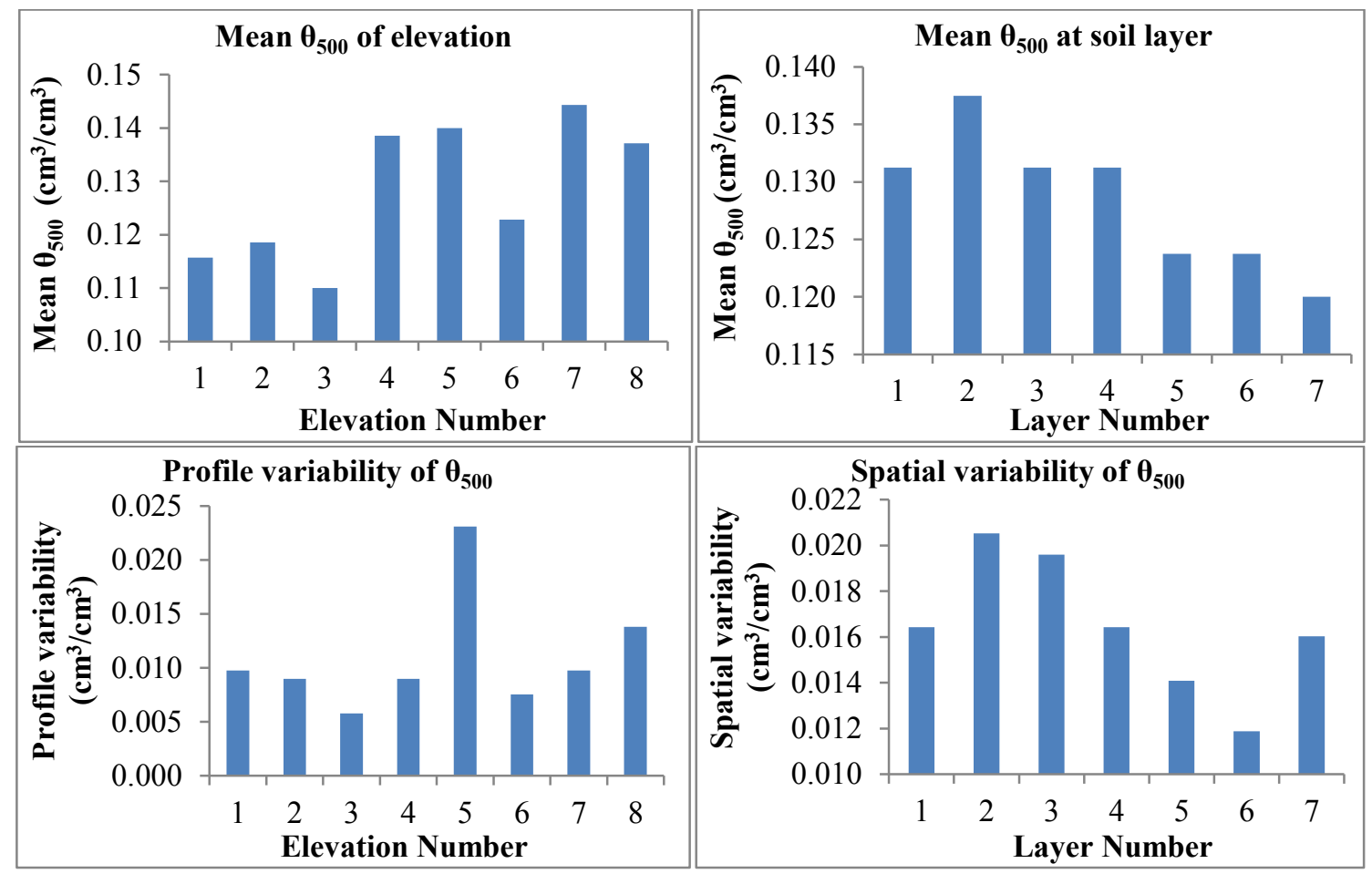

Figure 2: Different variables of $\theta_{500}$

The analysis was then done for the different variables of water retention at $-1000 \mathrm{kPa}$ pressure head, $\left(\theta_{1000}\right)$. At first, mean water retention at $-1000 \mathrm{kPa}$ was determined for different elevations. It was noticed that, mean water retention at $-1000 \mathrm{kPa}$ was less at the bottom elevations i.e. at 30,40 and $50 \mathrm{~m}$ ranging from $9.42 \%$ to $8.14 \%$. It increased in the fourth elevation (12.71\%) and in remaining elevations it was ranging from $10.57 \%$ to $11.86 \%$. Mean $\theta_{1000}$ at different layers was computed and observed that it was quite high in second layer about $11.25 \%$ compared to other layers. Then it was in the decreasing order from second layer to sixth layer $(11.25 \%$ to $9.63 \%)$.

More profile variability was observed in fifth elevation $(2.2 \%)$ and less in fourth and sixth elevations ranging from $0.76 \%$ to $0.79 \%$. In the remaining layers, it was almost same about 1.1 to $1.2 \%$. $1.46 \%$ spatial variability was observed in first layer and increased in third layer $(2.47 \%)$. In other layers it was almost same. The results are shown in Figure 3.

The analysis was then continued with the study of different variables of water retention at $-1500 \mathrm{kPa}$ pressure head, $\left(\theta_{1500}\right)$. Mean water retention at $-1500 \mathrm{kPa}$ was lower in the bottom three elevations $(7 \%)$, and then it drastically increased to $11.57 \%$ in the fourth elevation. In other top elevations, it was relatively less ranging from $8.71 \%$ to $10.14 \%$. Then mean $\theta_{1500}$ at different layers were computed; it was almost same in the top four layers about $9.13 \%$ to $9.5 \%$, and then it decreased to $8 \%$ in the other three bottom layers. More profile variability was observed in the fifth elevation about $1.77 \%$ and in other elevations small variations were found. Spatial variability was lower in the first layer (1.3\%), and in other layers it was almost same about $1.91 \%$ to $2.13 \%$ except in the fifth layer. Figure 4, shows the different variables of water retention at $-1500 \mathrm{kPa}$. 


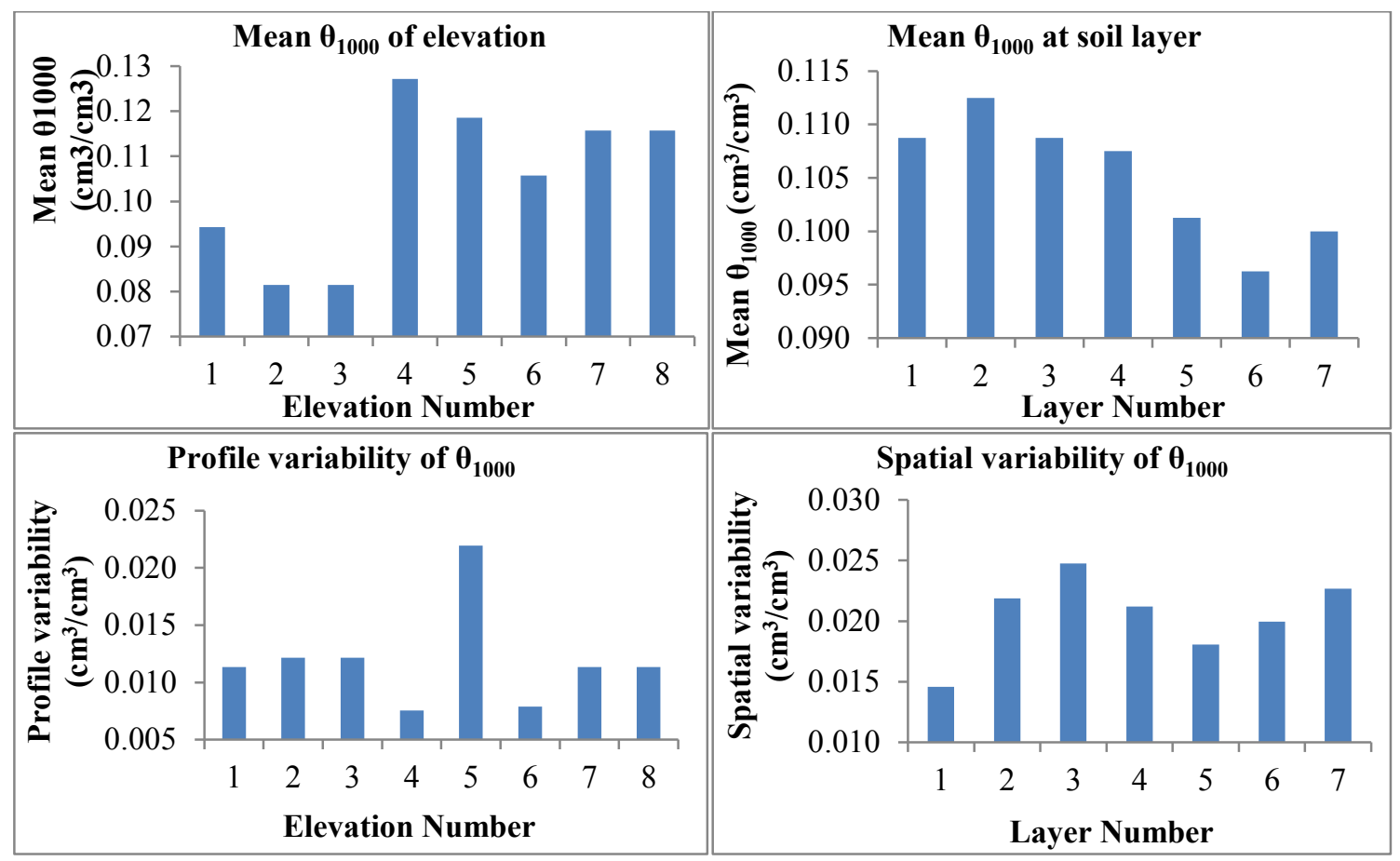

Figure 3: Different variables of $\theta_{1000}$

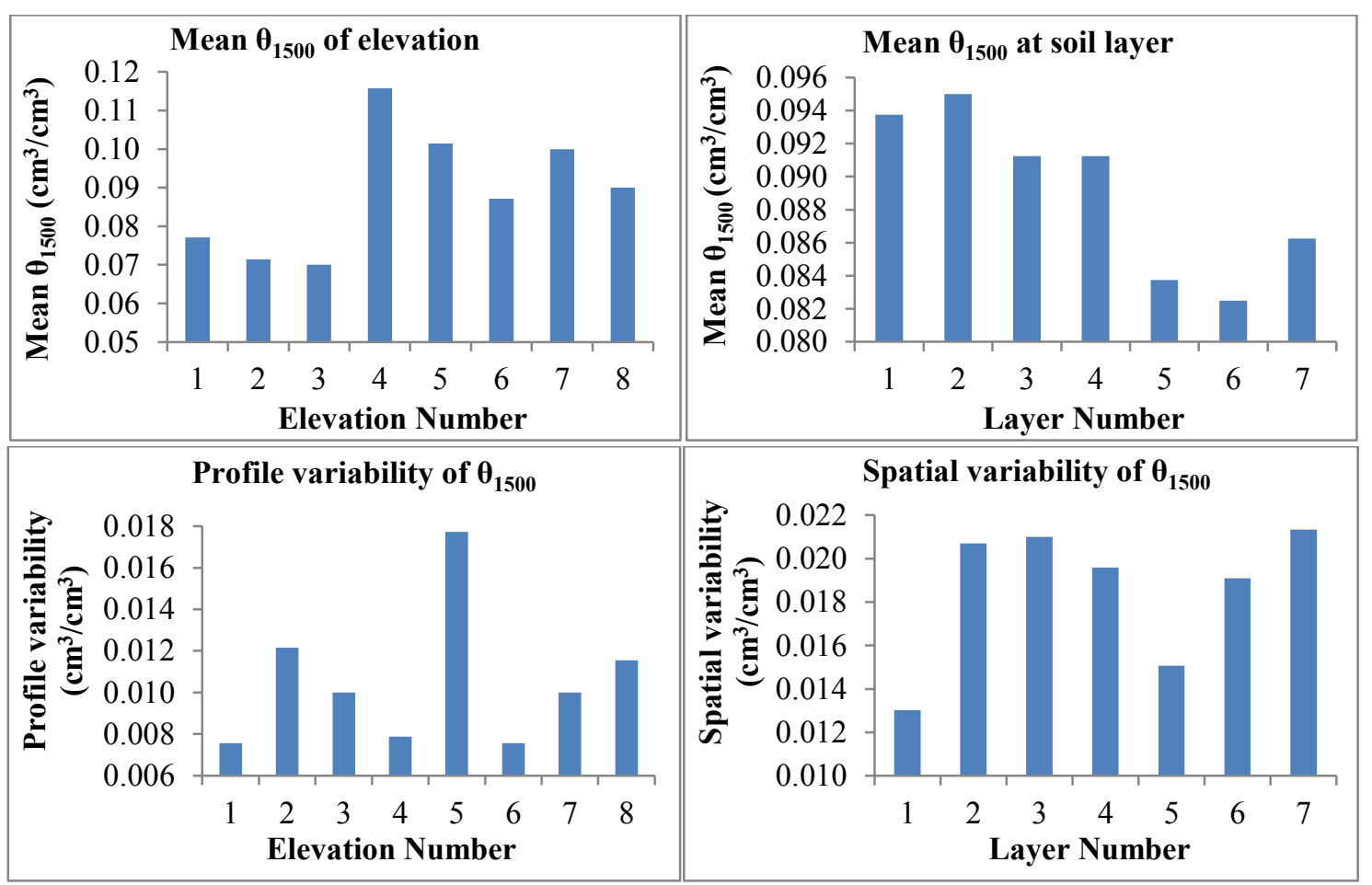

Figure 4: Different variables of $\theta_{1500}$

The different variables of saturated hydraulic conductivity $\left(\mathrm{k}_{\mathrm{s}}\right)$ were then computed and analyzed. Mean $\mathrm{k}_{\mathrm{s}}$ at different elevation was found out and it was more in third elevation. In lower elevations i.e., from first elevation to third elevation, mean $\mathrm{k}_{\mathrm{s}}$ was in increasing order, but then it decreased in fourth and fifth elevations, and again from fifth elevation it increased up to top most elevation. Mean $\mathrm{k}_{\mathrm{s}}$ at different layers was then studied; it was less in first layer. In the remaining layers not considerable variations were found. Profile variability was quite more in third elevation and less in first elevation; in the other elevations it was almost same. Spatial variability was 
more in third layer, less in first layer and in other layers small variations were observed. Figure 5, shows the different variables of saturated hydraulic conductivity $\left(\mathrm{k}_{\mathrm{s}}\right)$.

It can be observed that, in the present case, forested hillslope soils show highest soil water retention of 3\% at the top layer and $2.8 \%$ at the bottom most layer at -33 and $-100 \mathrm{kPa}$ pressure heads. Even at $-300 \mathrm{kPa}$, water retention was higher at the top layers and was lower at the bottom layers varying from $2.2 \%$ to $1.7 \%$. The changes observed across the different layers may be due to continuous inflow of water from the upper zone to the lower zone after every rainfall events. This may be the possible explanation for higher soil moisture retention in the top layers than that of other bottom layers. At $-500 \mathrm{kPa}$ pressure head, soil water retention was almost same in all the depths. At -1000 and $-1500 \mathrm{kPa}$, water retention was higher in the bottom layers than that of the top layers. As it has been reported by many researchers, the contribution of flow from bedrock to the soil may be another possible explanation for the persistence of soil water retention in the bottom layers of these hillslopes [7]. Saturated hydraulic conductivity was more in the top layers around $3.54 \mathrm{~cm} / \mathrm{hr}$ and then it decreased towards the bottom layers. The least saturated hydraulic conductivity was $1.44 \mathrm{~cm} / \mathrm{hr}$.

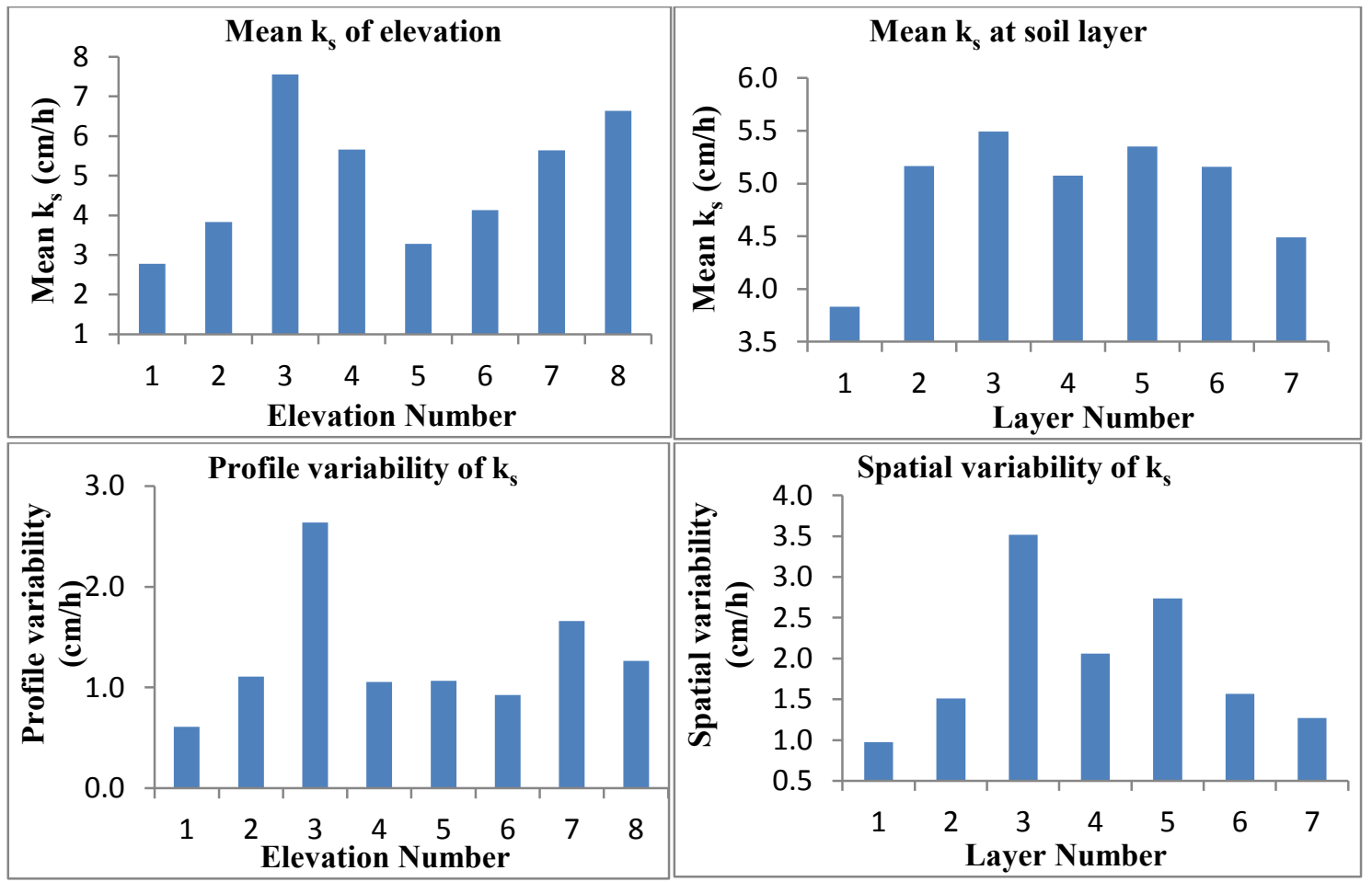

Figure 5: Different variables of saturated hydraulic conductivity $\left(\mathrm{k}_{\mathrm{s}}\right)$

\section{Conclusion}

Spatial variability of hydraulic properties of the soil is quite significant for heterogeneous unsaturated zone environments. Spatial variability was examined for hydraulic properties such as soil water retention data and saturated hydraulic conductivity at different depths for forested hillslope soil profiles. In order to gain a better understanding of soil variations in relation to land use and topography, the present study used correlation analysis to analyze the soil properties obtained from forest land covers. The aim was to characterize the different variables of soil properties i.e., mean of each soil property of the site, mean of each soil property at layers, profile variability of each soil property and spatial variability of each soil property at layers across forested hillslope soils. The forested hillslope soil of Pavanje river basin has more water retention capacity. The spatial variation of soil water retention at $-33,-100$ and $-300 \mathrm{kPa}$ pressure head in the forested hillslope soils is relatively high in the top layer and lowers at the bottom most layers. Spatial variation of saturated hydraulic conductivity is also similar to that of soil water retention.

\section{References}

[1]. Farajalla, N.S. and Vieux,B.E., Capturing the essential spatial variability in distributed hydrologic modeling: Infiltration Parameters, Journal of Hydrological Processes, 8, 55-68, 1995. 
[2]. Grayson, R.B., Western, A.W., Chiew, F.H.S. and Bloschl, G., Preferred states in spatial soil moisture patterns: local and nonlocal controls, Water Resources Research, 33, 2897-2908, 1997.

[3]. Biggar, J.W. and Nielsen, D.R., Spatial variability of the leaching characteristics of a field soil, Water Resource Research, 12, 78-84, 1976.

[4]. Famiglietti, J.S., Rudnicki, J.W. and Rodell, M., Variability in surface moisture content along a hillslope transects, Rattlesnake Hill Texas, Journal of Hydrology, 210, 259-281, 1998.

[5]. Loague, K., Soil water content at R-t., Part 1., Spatial and temporal variability, Journal of Hydrology, 139, 233-251, 1992.

[6]. Yang, Qiu, Bojie, Fu, Jun, Wang, and Liding, Chen, Soil moisture variation in relation to topography and land use in a hillslope catchment of the Loess Plateau, China, Journal of Hydrology, 240, 243-263, 2001.

[7]. Asano, Y., Uchida, T. and Ohte, N., Residence times and flow paths of water in steep channeled catchments, Tanakami, Japan, Journal of Hydrology, 261, 173-192, 2002. 